\title{
Micro/nano-textured hierarchical titanium topography promotes exosome biogenesis and secretion to improve osseointegration
}

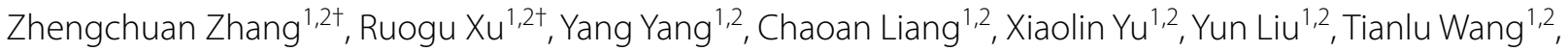

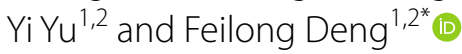

\begin{abstract}
Background: Micro/nano-textured hierarchical titanium topography is more bioactive and biomimetic than smooth, micro-textured or nano-textured titanium topographies. Bone marrow mesenchymal stem cells (BMSCs) and exosomes derived from BMSCs play important roles in the osseointegration of titanium implants, but the effects and mechanisms of titanium topography on BMSCs-derived exosome secretion are still unclear. This study determined whether the secretion behavior of exosomes derived from BMSCs is differently affected by different titanium topographies both in vitro and in vivo.

Results: We found that both micro/nanonet-textured hierarchical titanium topography and micro/nanotubetextured hierarchical titanium topography showed favorable roughness and hydrophilicity. These two micro/nanotextured hierarchical titanium topographies enhanced the spreading areas of BMSCs on the titanium surface with stronger promotion of BMSCs proliferation in vitro. Compared to micro-textured titanium topography, micro/nanotextured hierarchical titanium topography significantly enhanced osseointegration in vivo and promoted BMSCs to synthesize and transport exosomes and then release these exosomes into the extracellular environment both in vitro and in vivo. Moreover, micro/nanonet-textured hierarchical titanium topography promoted exosome secretion by upregulating RAB27B and SMPD3 gene expression and micro/nanotube-textured hierarchical titanium topography promoted exosome secretion due to the strongest enhancement in cell proliferation.
\end{abstract}

Conclusions: These findings provide evidence that micro/nano-textured hierarchical titanium topography promotes exosome biogenesis and extracellular secretion for enhanced osseointegration. Our findings also highlight that the optimized titanium topography can increase exosome secretion from BMSCs, which may promote osseointegration of titanium implants.

Keywords: Micro/nanonet-textured hierarchical titanium topography, Micro/nanotube-textured hierarchical titanium topography, Bone marrow mesenchymal stem cells, Exosomes, Osseointegration

*Correspondence: dengfl@mail.sysu.edu.cn

${ }^{\dagger}$ Zhengchuan Zhang and Ruogu Xu contributed equally to this work 1 Department of Oral Implantology, Hospital of Stomatology, Guanghua School of Stomatology, Sun Yat-Sen University, No.56 of LingYuanXiLu, Guangzhou 510055, Guangdong, People's Republic of China

Full list of author information is available at the end of the article

\begin{abstract}
Background
Dental implants in patients with osteoporosis have a failure rate of over $10 \%$ due to decreased alveolar bone density and poor regeneration ability after tooth loss $[1,2]$. The proliferation and osteogenic differentiation capacities of bone marrow mesenchymal stem cells (BMSCs) in osteoporotic patients are inhibited [3]. BMSCs and secretome products derived from BMSCs play important
\end{abstract}

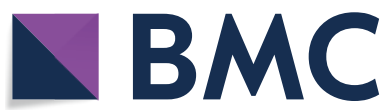

(c) The Author(s) 2021. This article is licensed under a Creative Commons Attribution 4.0 International License, which permits use, sharing, adaptation, distribution and reproduction in any medium or format, as long as you give appropriate credit to the original author(s) and the source, provide a link to the Creative Commons licence, and indicate if changes were made. The images or other third party material in this article are included in the article's Creative Commons licence, unless indicated otherwise in a credit line to the material. If material is not included in the article's Creative Commons licence and your intended use is not permitted by statutory regulation or exceeds the permitted use, you will need to obtain permission directly from the copyright holder. To view a copy of this licence, visit http://creativeco mmons.org/licenses/by/4.0/. The Creative Commons Public Domain Dedication waiver (http://creativecommons.org/publicdomain/ zero/1.0/) applies to the data made available in this article, unless otherwise stated in a credit line to the data. 
roles in osseointegration between bone and titanium implants $[4,5]$. The surface design of titanium implants has been highlighted to optimize a favorable titanium topography on the biological responses of BMSCs $[6$, 7]. However, much less is known about the role of titanium topography in the regulation of BMSCs-derived secretome products.

Exosomes, which are synthesized and secreted by various cell types as extracellular vesicles (EVs) [8], convey nucleic acids, proteins, lipids, and other active molecules into neighboring cells for cell-to-cell communication [9, 10]. The interactions among titanium implants, BMSCs, and exosomes are vital in the process of osseointegration [5]. It was shown in vivo and in vitro that exosomes secreted by BMSCs enhance adhesion, proliferation, and osteogenic differentiation of BMSCs and facilitate improved bone regeneration with a high concentration of exosomes by activating the PI3k/Akt pathway [11-13]. The small GTPase Rab27 and the sphingomyelin phosphodiesterase 3 (SMPD3) pathway control the synthesis and secretion of exosomes $[14,15]$. The release of exosomes was notably reduced in Rab27-knockdown and SMPD3-inhibited cells using shRNA and GW4869 respectively [16, 17]. Recently, exosomes-integrated titanium disks were constructed with favorable biofunctionality for targeted osteogenesis by enhancing the adhesion, proliferation, and osteogenic differentiation of BMSCs [5, 18]. The physicochemical characteristics of titanium surfaces have been reported to affect the biological behavior and function of stem cells [19-21]. However, how titanium topography influences the secretion of exosomes from BMSCs is not clear.

Recently, customized titanium implants in intricately edentulous ridges have become possible with the rapid developments in the latest additive manufacturing (Selective Laser Melting, SLM), allowing for precisely controlled implant design [22, 23]. Moreover, the interface behavior between bone and SLM implants has been shown to be superior to the turned implants but inferior to that of commercial implants due to the excessive surface roughness of the SLM implants [24]. Surface modifications of turned or native-SLM titanium topography have been widely studied for improved performance of BMSCs on dental implants by constructing biomimetic topographies similar to the microstructure of bone tissue $[25,26]$. Hierarchical porous structures have been widely studied as a nanocarrier for gene delivery and a framework for tissue regeneration [27-29]. Micro/ nano-textured hierarchical titanium topographies have been reported to be more bioactive and biomimetic than smooth, native-SLM or micro-textured titanium topographies for enhanced osteogenic differentiation of BMSCs and bone-implant osseointegration in vitro and in vivo
[30, 31]. Surface modifications of micro/nano-textured hierarchical titanium topographies usually occur through anodic oxidation, alkali-heat treatment, or electrochemical deposition on the micro-textured titanium base by sandblasting or acid etching [30, 32, 33]. In vitro studies have shown that micro/nano-textured topographies with combined acid etching and anodic oxidation techniques or combined acid etching and alkali-heat treatment techniques significantly enhance BMSCs behavior on the titanium surface [34,35]. These studies focus only on the proliferation and osteogenic differentiation results of BMSCs under the designed topography. The precise mechanisms of micro/nano-textured topography-cell interactions for the enhanced BMSCs bioactivity and osseointegration are not known. Considering the importance of BMSCs-derived exosomes in osseointegration, micro/nano-textured topography may influence exosome secretion from BMSCs and then regulate cell-titanium activity and cell-cell communication on the titanium surface.

In this study, we determined whether the secretion behavior of exosomes derived from BMSCs is differently affected by different titanium topographies. Furthermore, we sought to explore the effect and mechanism of titanium topography on BMSCs-derived exosome secretion both in vivo and in vitro.

\section{Results}

\section{Surface characterization}

Field-emission scanning electron microscopy (FE-SEM) was used to determine the surface topographies of each group. The SLM samples showed rough and waved surfaces with some unmelted titanium spheres (diameter $28.29 \pm 0.64 \mu \mathrm{m})$ (Fig. 1a, b). The SLA samples displayed well-distributed micrometer-sized pits (average diameter $5.62 \pm 0.65 \mu \mathrm{m}$ ) without residual particles from the SLM samples after sandblasting and acid etching (Fig. 1d, e). Nano-textured titanium topography was not found on the surfaces of either the SLM or SLA samples. At low magnification, the SAH and SAO samples showed the same shallow pitted surfaces over $1 \mu \mathrm{m}$ in diameter similar to the micrometer-sized pits on the SLA surface (Fig. 1g, j). At high magnification, bionic structures with interpenetrating hierarchical nanonets were observed on the SAH samples with $301.52 \pm 51.22 \mathrm{~nm}$ large pores outside and $76.27 \pm 15.57 \mathrm{~nm}$ small pores inside (Fig. 1h). Uniformly arranged nanotubes (average diameter $55.36 \pm 6.16 \mathrm{~nm}$ ) were formed on the SAO samples (Fig. 1k).

The surface roughness results (Sa and $\mathrm{Sq}$ ) are shown in Table 1. The SLM samples exhibited significantly higher Sa and Sq values than those of the SLA $(p<0.05)$, SAH $(p<0.05)$, and SAO samples $(p<0.05)$. There were 


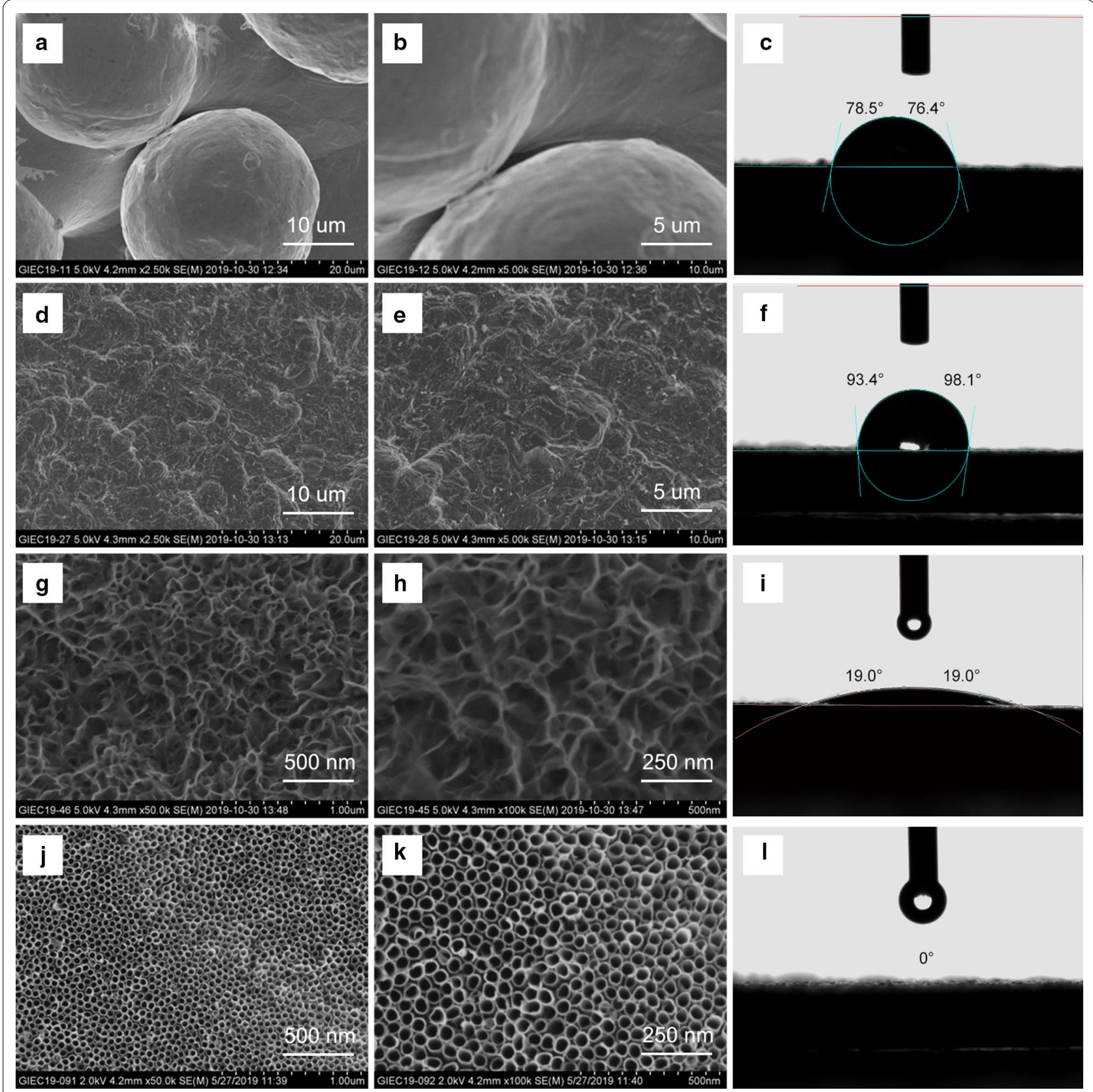

Fig. 1 SEM images and water contact angles of the SLM, SLA, SAH, and SAO samples. SEM images of the SLM group at 2500x magnification (a) and at $5000 \times$ magnification (b). Water contact angle of $77.5 \pm 1.1^{\circ}$ for the SLM group (c). SEM images of the SLA group at 2500x magnification (d) and at 5000 $\times$ magnification (e). Water contact angle of $95.8 \pm 2.4^{\circ}$ for the SLA group (f). SEM images of the SAH group at 50,000 $\times$ magnification ( $\left.\mathbf{g}\right)$ and at 100,000 $\times$ magnification (h). Water contact angle of $19.0 \pm 0^{\circ}$ for the SAH group (i). SEM images of the SAO group at 50,000 $\times$ magnification (j) and at 100,000 $\times$ magnification (k). Water contact angle of $0 \pm 0^{\circ}$ for the SAO group (I) 
Table 1 Surface roughness results of each titanium topography $(n=3)$

\begin{tabular}{llc}
\hline Sample & Sa $(\mu \mathrm{m})$ & Sq $(\mu \mathrm{m})$ \\
\hline SLM & $13.05 \pm 0.25^{\mathrm{bcd}}$ & $16.51 \pm 0.20^{\mathrm{bcd}}$ \\
SLA & $4.21 \pm 0.57^{\mathrm{a}}$ & $5.07 \pm 0.47^{\mathrm{a}}$ \\
SAH & $4.19 \pm 0.21^{\mathrm{a}}$ & $5.24 \pm 0.26^{\mathrm{a}}$ \\
SAO & $4.57 \pm 0.17^{\mathrm{a}}$ & $5.89 \pm 0.51^{\mathrm{a}}$ \\
\hline
\end{tabular}

$a, b, c$, and d indicate significant difference compared to SLM, SLA, SAH, and SAO respectively $(p<0.05)$

no significant differences among the SLA, SAH, and, SAO surfaces $(p>0.05)$.

The water contact angles of the SLM, SLA, SAH, and SAO samples were $77.5 \pm 1.1^{\circ}, 95.8 \pm 2.4^{\circ}, 19.0 \pm 0^{\circ}$, and $0 \pm 0^{\circ}$, respectively (Fig. 1c, f, i, and l). The SAH surface showed favorable hydrophilicity, while the SAO surfaces displayed superhydrophilicity.

\section{Identification of hBMSCs}

Surface marker expression was confirmed using flow cytometry. hBMSCs showed an over $99 \%$ positive rate for mesenchymal stem cell markers (CD73, CD90, CD105, and $\mathrm{CD} 29$ ) and the absence of hematopoietic surface antigens (CD45, CD19, CD34, HLA-DR, and CD11b) (Fig. 2a-i).

The osteogenic, adipogenic, and chondrogenic differentiation potential of the hBMSCs was determined compared to the noninduced group. After 11 days under osteogenic differentiation culture conditions, the cells showed extracellular calcium depositions by Alizarin red staining (Fig. 2j, k). After 11 days under adipogenic differentiation culture conditions, the cells showed lipid inclusion formation by oil red $\mathrm{O}$ staining (Fig. 2l, m). After 21 days under the chondrogenic differentiation culture conditions, the slices of cell conglomerates displayed proteoglycan depositions and cartilage lacuna formation by safranin O staining (Fig. 2n, o).

\section{Cell viability evaluation}

Cell adhesion and morphology were evaluated by SEM. Cells on the SLM and SLA samples were polygonal with short lamellipodia (Fig. 3a, b). Elongated cell bodies with finger-like filopodia protrusions were found in both the SAH and SAO samples and tiny protrusions were extended from these cells into the micro/nano-textured hierarchical titanium structure (Fig. 3c, d).

Cell proliferation was evaluated by CCK- 8 assay (Fig. 3e). On the first day, there were no significant
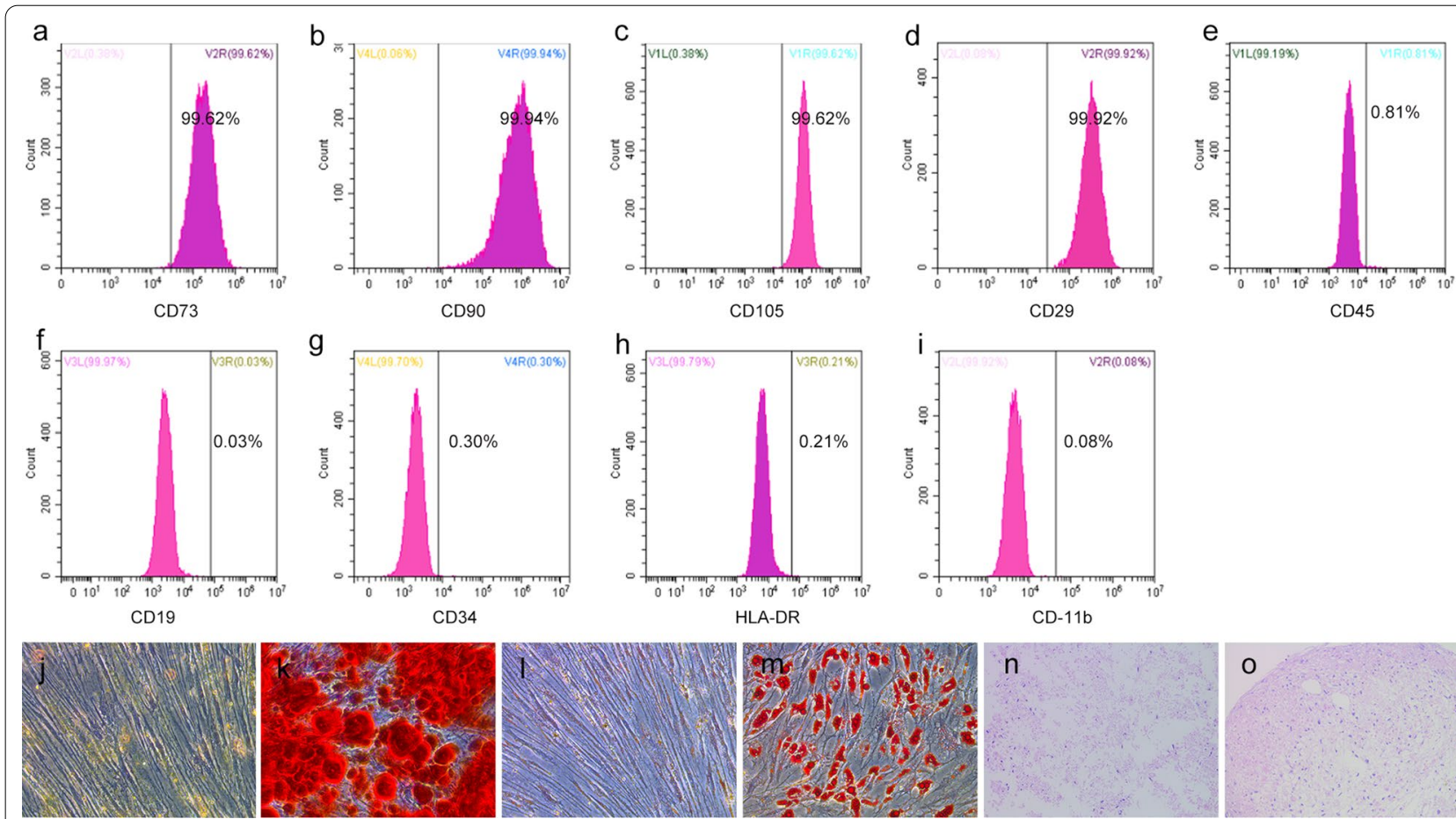

$\mathrm{n}$

o

Fig. 2 The immunophenotypic and differentiation potential results of hBMSCs were determined. Surface antigen markers results of mesenchymal stem cells (a-d). Surface antigen markers results of hemopoietic cells (e-i). The staining results for non-induction, osteogenic, lipogenic and chondrogenic induced differentiation of hBMSCs at 200x magnification by Alizarin red staining of non-induction (j) and osteogenic induction (k),

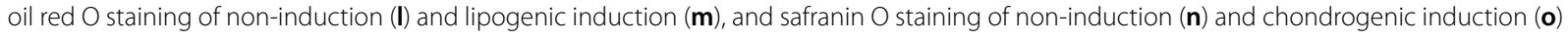



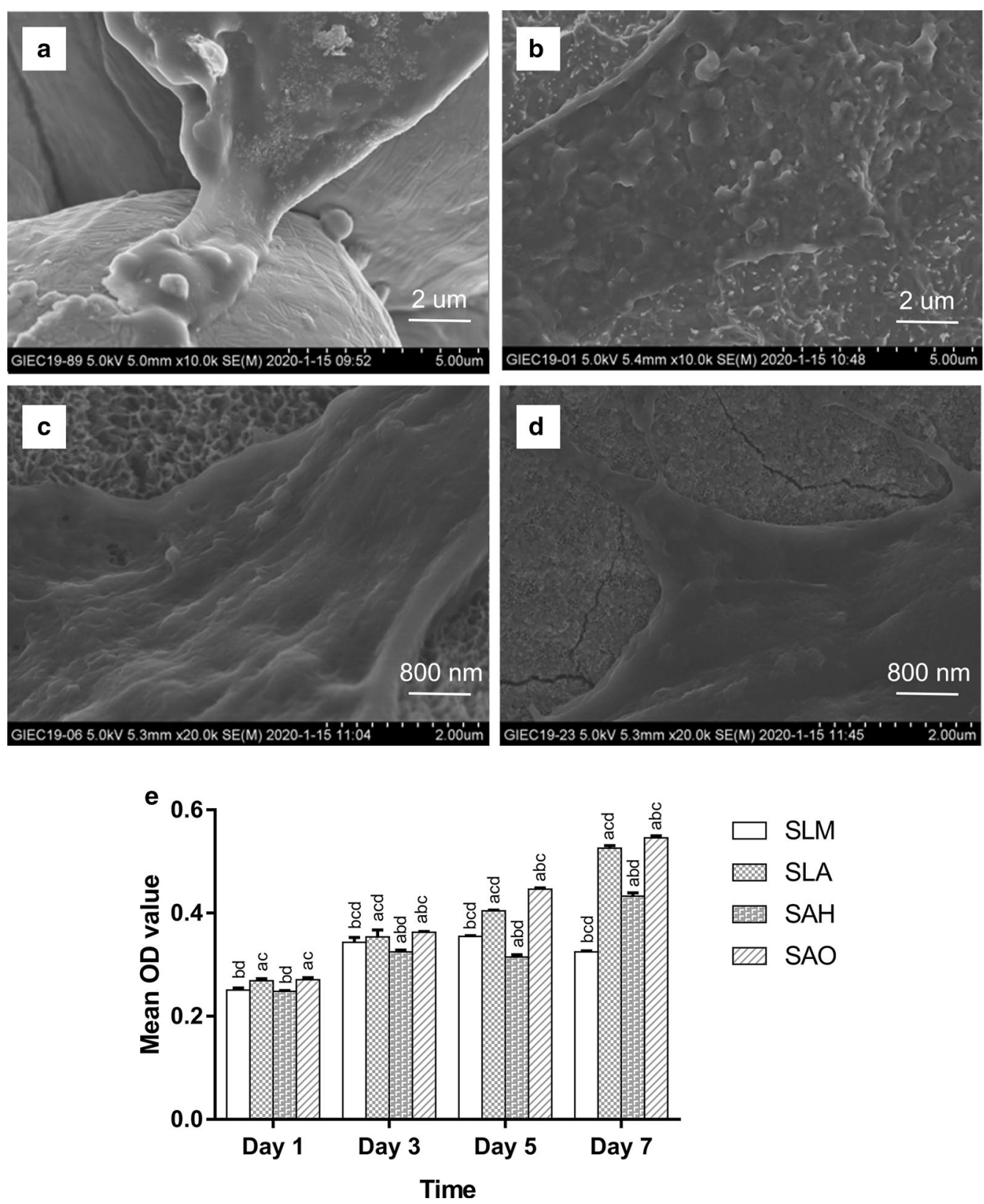

Fig. 3 The cell adhesion, morphology, and proliferation of hBMSCs on the titanium surface of each group. SEM images of BMSCS on the SLM

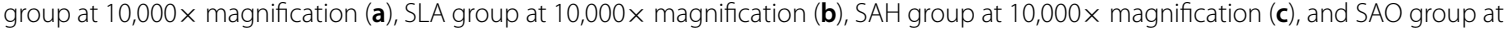
$10,000 \times$ magnification (d). Cell proliferation evaluation of hBMSCs on the titanium surface of each group after 1, 3, 5 and 7 days by CCK-8 (e) $(n=3)$. a-d above each bar indicate significant difference compared to SLM, SLA, SAH, SAO respectively $(p<0.05)$.

differences between the SAO and SLA group $(p>0.05)$, or between the SAH and SLM group $(p>0.05)$. The SAO group with micro/nanotube-textured hierarchical titanium topography had the strongest promotion of hBMSCs proliferation on the third, fifth, and seventh days $(p<0.05)$, followed by the SLA group with micro-textured titanium topography and the SAH group with micro/ nanonet-textured hierarchical titanium topography.

\section{Characterization of the hBMSCs-derived exosomes}

The hBMSCs-derived exosomes showed monolayer membrane vesicles with round grape-like structures (Fig. 4a). The particle size distribution of the samples was $30-150 \mathrm{~nm}$ (median \pm SD, $73.0 \pm 18.7 \mathrm{~nm}$ ) in diameter by nano-flow cytometry (Fig. 4b). Flow cytometry analysis of the samples demonstrated positive expression of both CD63 (56.8\%) and CD81 (50.8\%), which are markers of 
exosomes (Fig. 4c, d). Moreover, western blotting analysis showed that the hBMSCs-derived exosomes demonstrated positive expression for exosome markers (CD63, and TSG101) and the absence of endoplasmic reticulum antigen (Calnexin) (Fig. 4e).

\section{Effects of titanium topography on exosome secretion via AChE activity}

Exosomes released into the supernatant were quantitatively measured via the AChE activity of the isolated exosomes (Fig. 5). The activities of acetylcholinesterase were significantly higher in the SAH and SAO groups than in the SLM and SLA groups $(p<0.05)$. Moreover, the SLA group secreted significantly more exosomes than the SLM group $(p<0.05)$.

\section{Intracellular CD63 distribution on different titanium topographies}

Immunofluorescent staining results revealed similar cell nuclei of the four groups, and similar adhesion and morphology results were observed in the cell viability evaluation. Cells on the SLA samples (Fig. 6b) showed more spreading areas and intracellular CD63 distribution than those on the SLM samples (Fig. 6a). Cells in the SAH (Fig. 6c) and SAO (Fig. 6d) groups with elongated cell bodies connected to neighboring cells had more intracellular CD63 distribution than cells in the SLM and SLA groups.

\section{Effects of titanium topography on gene and protein expression levels related to exosome secretion}

Previous reports have shown that the Rab27 family and SMPD3 signaling control exosome secretion in a series of steps. After culturing for $48 \mathrm{~h}$, the relative mRNA expression levels were determined by qRT-PCR (Fig. 7a). The micro/nanonet-textured hierarchical titanium topography significantly increased the mRNA levels of RAB27A, $\mathrm{RAB} 27 \mathrm{~B}$, and SMPD3 compared to the other three groups $(p<0.05)$, but there was no significant difference in the mRNA levels between the SAO and SLA groups $(p>0.05)$. After culturing for $48 \mathrm{~h}$, the relative protein expression levels were determined by WB (Fig. 7b, c). Micro/nanonet-textured hierarchical titanium topography significantly increased the protein abundance of RAB27B and SMPD3 compared to the other three groups $(p<0.05)$, but there was no significant difference in SYTL4 expression (a Rab27 effector) among the SAH, SAO, and SLA groups $(p>0.05)$. The SLM group showed significantly higher SMPD3 protein expression than the micro/nanotube-textured hierarchical titanium topography group $(p<0.05)$.

\section{Effects of titanium topography on exosome secretion and osseointegration in vivo}

On the 7th day after implant placement, H\&E staining of the implant sites showed clear threads and coronal-toapical aligned osteogenic cells. No infiltration superiorities of inflammatory cells in the bone-implant interface were protruding in any of the four groups (Fig. 8a). The exosome levels in the bone-implant interface were detected by a CD63 immunohistochemical assay. The expression levels of CD63 were significantly higher in the SAH and SAO groups than in the SLM and SLA groups $(p<0.05)$ (Fig. 8b, c). Periostin (a marker for mesenchymal stem cells)-positive cells were observed and quantified. The expression levels of periostin were significantly higher in the SAH and SAO groups than in the SLM and SLA groups $(p<0.05)$ (Fig. 8d, e), which was consistent with the exosome expression levels. No significant differences in the expression levels of CD11b (a marker for tissue macrophages) were found among the four groups $(p>0.05)$, but CD11b-positive cells gathered close to the bone-implant interface (Fig. 8f, g).

On the 28th day after implant placement, histological analysis revealed that the BIC ratios of the SAH and SAO groups were significantly higher than those of the SLM and SLA groups $(p<0.05)$ (Fig. 8h, i).

\section{Discussion}

To our knowledge, this is the first observation that the micro/nano-textured titanium topography can influence exosome secretion from BMSCs in vitro and in vivo. In our experiments, we found that micro/nanonet-textured hierarchical titanium topography and micro/nanotubetextured hierarchical titanium topography showed favorable roughness and hydrophilicity. Micro/nanotextured hierarchical titanium topography enhanced the spreading areas of BMSCs on the titanium surface with a stronger promotion of BMSCs proliferation in vitro and osteointegration in vivo. Compared to micro-textured titanium topography, micro/nano-textured hierarchical titanium topography significantly promoted

(See figure on next page.)

Fig. 4 Characterization of hBMSCs derived exosomes. Transmission electron micrograph image of exosomes (a). Particle size distribution with the size range of exosomes by Flow NanoAnalyzer (b). CD63 surface antigen marker of exosomes by flow cytometry (c). CD81 surface antigen marker of exosomes by flow cytometry (d). Representative western blots showing exosome markers (CD9, CD63 and TSG101) and an intracellular marker (Calnexin) of the exosome sample (Exo) and controlled culture medium with 10\% exosome-depleted FBS (Con) (e) 
a

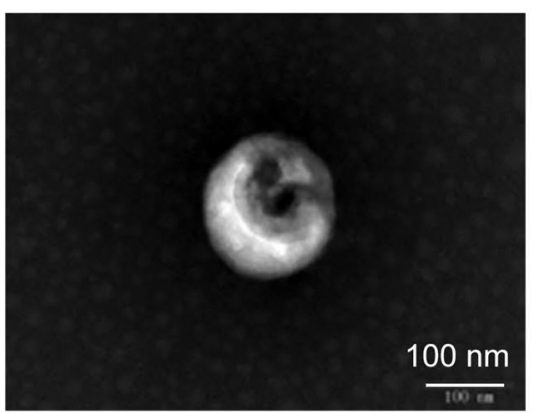

b

CONTROL

C Control-NC

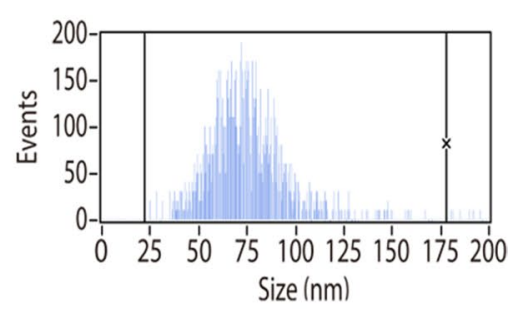

Control-CD63

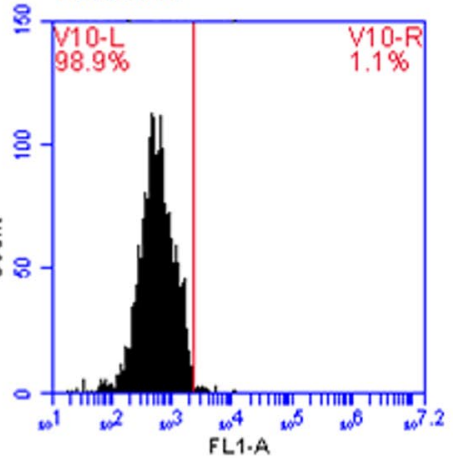

Gate: P1

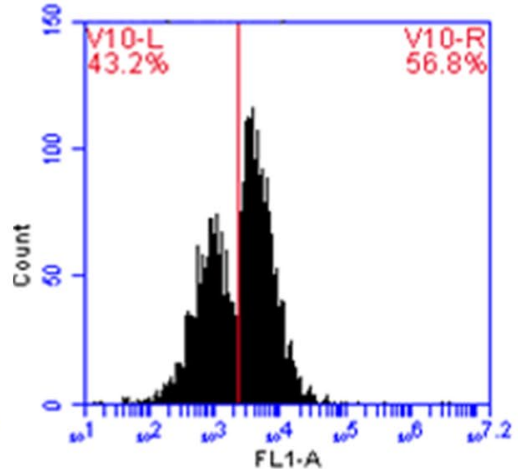

d

Control-NC

Gate: P1

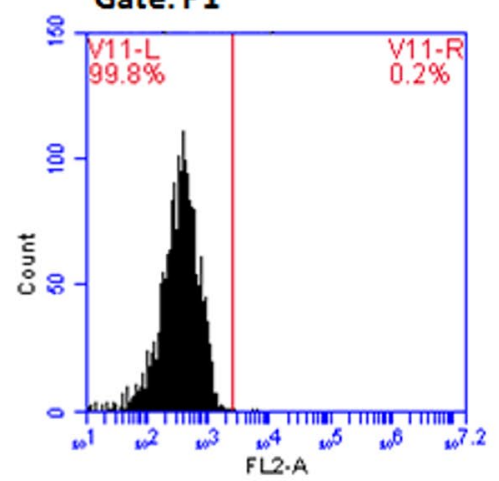

Control-CD81

Gate: P1

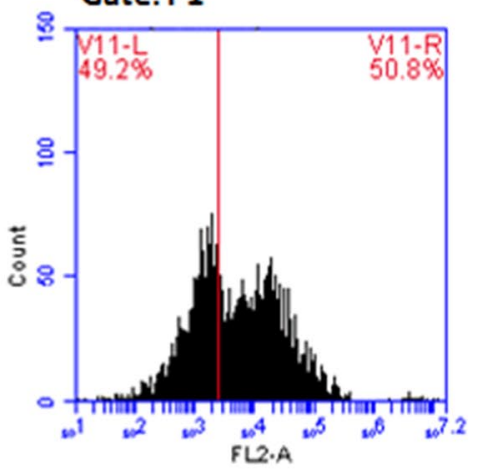

e

Exo Con

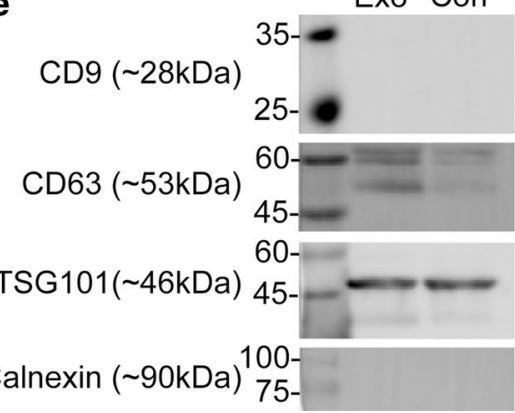




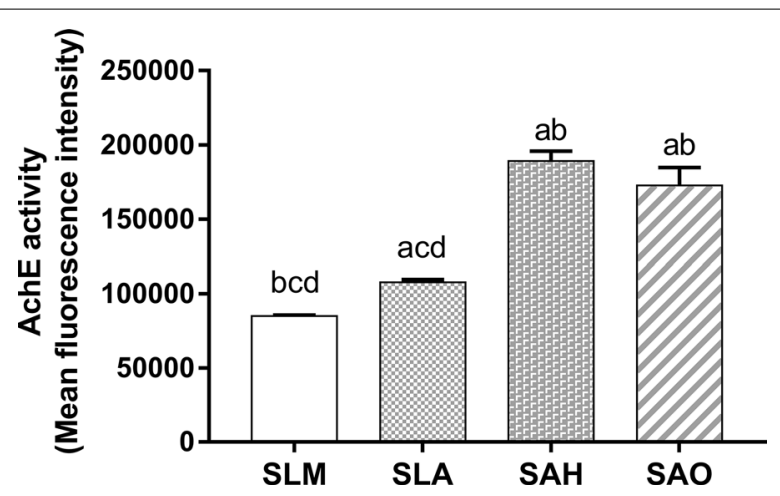

Fig. 5 Topography effect of titanium surface on AChE activity of hBMSCs derived exosomes $(n=3)$. The relative numbers of the exosomes in the supernatant from hBMSCs on the SLM, SLA, SAH, and $\mathrm{SAO}$ samples were determined by the fluorescence values of the exosome samples at $590 \mathrm{~nm}$ emission detection. a-d above each bar indicate significant difference compared to SLM, SLA, SAH, SAO respectively $(p<0.05)$

BMSCs to synthesize and transport exosomes and then release these exosomes into the extracellular environment. Moreover, micro/nanonet-textured hierarchical titanium topography promoted exosome secretion by upregulating RAB27B and SMPD3 gene expression and micro/nanotube-textured hierarchical titanium topography promoted exosome secretion due to the strongest enhancement in cell proliferation.

In our study, micro/nano-textured titanium topography was constructed based on the 3D-printed titanium disks using a selective laser melting technique with one-step molding, high precision, good mechanics, high digitization, customized design, and many other advantages [36, 37]. After sandblasting and acid etching, the unmelted titanium spheres were removed and well-distributed micrometer-sized pits were formed. There are many common acid etching processing methods to remove residual particles during the process of sandblasting by dissolving titanium oxide layers, such as the use of hydrochloric acid $(\mathrm{HCl})$, hydrofluoric acid $(\mathrm{HF})$, nitric acid $\left(\mathrm{HNO}_{3}\right)$, sulfuric acid $\left(\mathrm{H}_{2} \mathrm{SO}_{4}\right)$, and mixed acid solutions $\left(\mathrm{HCl} / \mathrm{H}_{2} \mathrm{SO}_{4}\right.$ or $\left.\mathrm{HF} / \mathrm{H}_{2} \mathrm{SO}_{4}\right)$, but the titanium topography differs with the changes in acid concentration, treatment time and temperature [38-40]. We used a 5\% HF solution treated for $2 \mathrm{~min}$ at room temperature and successfully constructed micro-textured titanium topography with superior time and operability [33, 41].

Nanoscale structures can improve the tissue response of osteoblasts, enhance osseointegration, reduce bacterial adhesion, and construct a drug delivery system [42]. Both the SAH and SAO samples showed shallow pitted surfaces with diameters of over $1 \mu \mathrm{m}$ similar to the micrometer-sized pits on the SLA surface. After alkali-heat and anodic oxidation treatments, micro/nanonet-textured and micro/nanotube-textured hierarchical titanium topographies were formed, respectively. The micro/ nanonet-textured hierarchical titanium topography with small and large nanoscale-sized pores is similar to the structure of the extracellular matrix (ECM) structure, which can provide the location and space in different directions for cell growth [43, 44]. Some studies have indicated that uniformly arranged titanium nanotubes with an average diameter of $70 \mathrm{~nm}$ possess favorable wettability, protein adsorption capacity, and antibacterial properties for improved osteogenesis [45-47]. In our study, an average nanotube diameter of $55.36 \mathrm{~nm}$ was produced, which should be beneficial for cell growth. A clear future challenge is optimization of the precise and repeatable micro/nano-textured hierarchical titanium topography.

A moderately rough (Sa 1-2 $\mu \mathrm{m})$ and hydrophilic surface with different nanoscale structures can induce a predominant cellular response [48]. The roughness values are mainly influenced by the microscale structures, causing excessive surface roughness of the SLM samples due to the partially melted particles. Therefore, alkali-heat and anodic oxidation treatments for nanoscale structures could not decrease the roughness of the SLA samples, because the SLA, SAH, and SAO samples have similar microscale structures [49]. In contrast, the nanoscale structures are the determining factor of titanium hydrophilicity with a favorable microenvironment for osteogenesis and long-term maintenance of peri-implant bone level $[50,51]$.

The precise mechanisms for enhanced topographyrelated BMSCs spreading, adhesion, and proliferation are not known. In this study, micro/nano-textured titanium topography promoted the adhesion and proliferation of BMSCs on titanium surfaces. BMSCs tend to grow on an appropriate surface with a moderately rough and nanotextured topography, on which the finger-like filopodia protrusions extend into the nanonet or nanotube, leading to the formation of ECM and new bone [52, 53]. However, the SAH samples may not have clear cell proliferation superiority due to its highly spreading morphology with the restricted total area compared to the SLA samples with smaller cell bodies.

Exosomes secreted by BMSCs were extracted from the supernatant by an exosome isolation kit and identified in terms of morphology, particle size distribution, and antigen markers. Western blot and flow cytometry analysis showed that the extracted exosomes expressed CD63, CD81 and TSG101, which are commonly enriched in exosomes. The exosomes in this study showed high purity after measuring the positive rates of CD63 (56.8\%) and CD81 (50.8\%), similar to the gold 

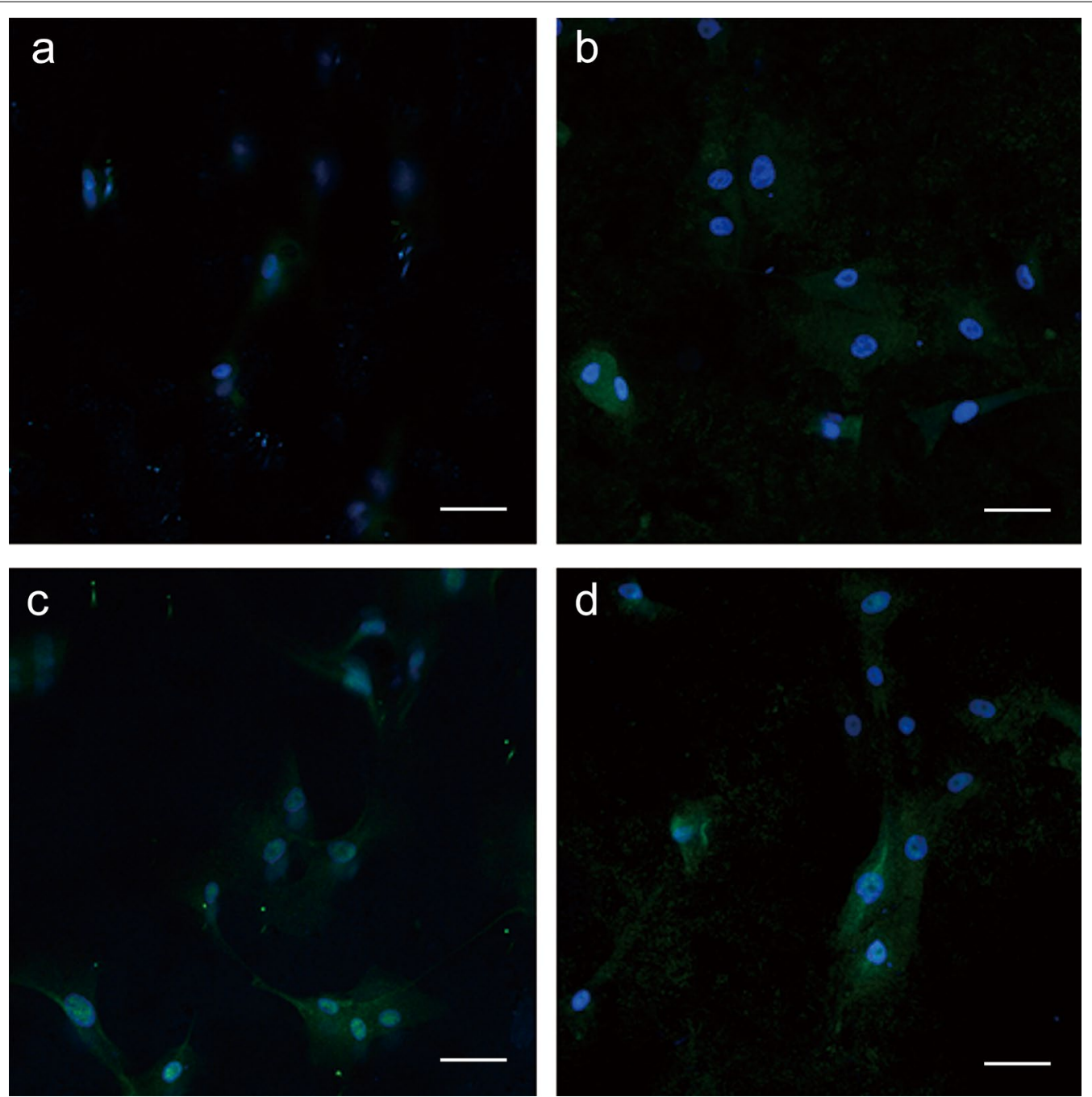

Fig. 6 The adhesion morphology, nucleus, content, and distribution of intracellular CD63 of hBMSCs on each sample after co-culture for $48 \mathrm{~h}$ at $20 \times$ magnification. Confocal laser scanning microscope images of the SLM (a), SLA (b), SAH (c), and SAO (d) group (blue fluorescence, nucleus staining with DAPl; green fluorescence, CD63 staining with Alexa Fluor 488; scale bar $=50 \mu \mathrm{m}$ )

isolation standard using the ultracentrifugation method with $46.0 \%$ and $55.0 \%$ positive percentages of CD63 and CD81 [54]. Based on quantitative results, micro/ nano-textured hierarchical titanium topography significantly promoted BMSCs to synthesize and transport exosomes and then release these exosomes into the extracellular environment via AChE activity and intracellular CD63 evaluation, as described previously [15, 55]. The CD63 expression levels in the bone-implant interface complemented the findings in vitro.

The small GTPase Rab27 and the sphingomyelin phosphodiesterase 3 (SMPD3) pathway control the synthesis and secretion of exosomes [15, 56]. Our findings demonstrated that micro/nanonet-textured hierarchical titanium topography promoted exosome secretion by upregulating RAB27B and SMPD3 gene expression. However, SAO samples have no clear secretion superiority of exosome-related gene and protein expression due to the strongest enhancement in cell proliferation, which may exert very large numbers of cells to secrete exosomes. There were increased mesenchymal and osteoprogenitor positive cells around the titanium implants in vivo, as described previously [57], and therefore, the osteogenic effects of micro/nanotextured hierarchical titanium topography may be explained by increased numbers of BMSCs and stimulation of exosome secretion from BMSCs based on the in vitro results of the present study and other studies 


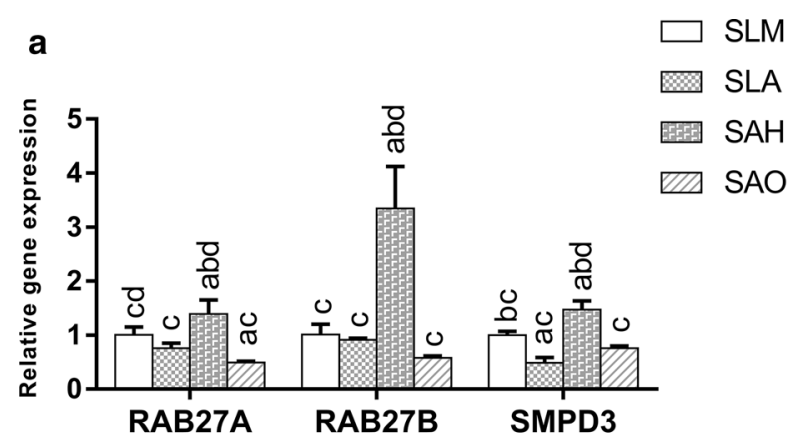

C

SLM SLA SAH SAO
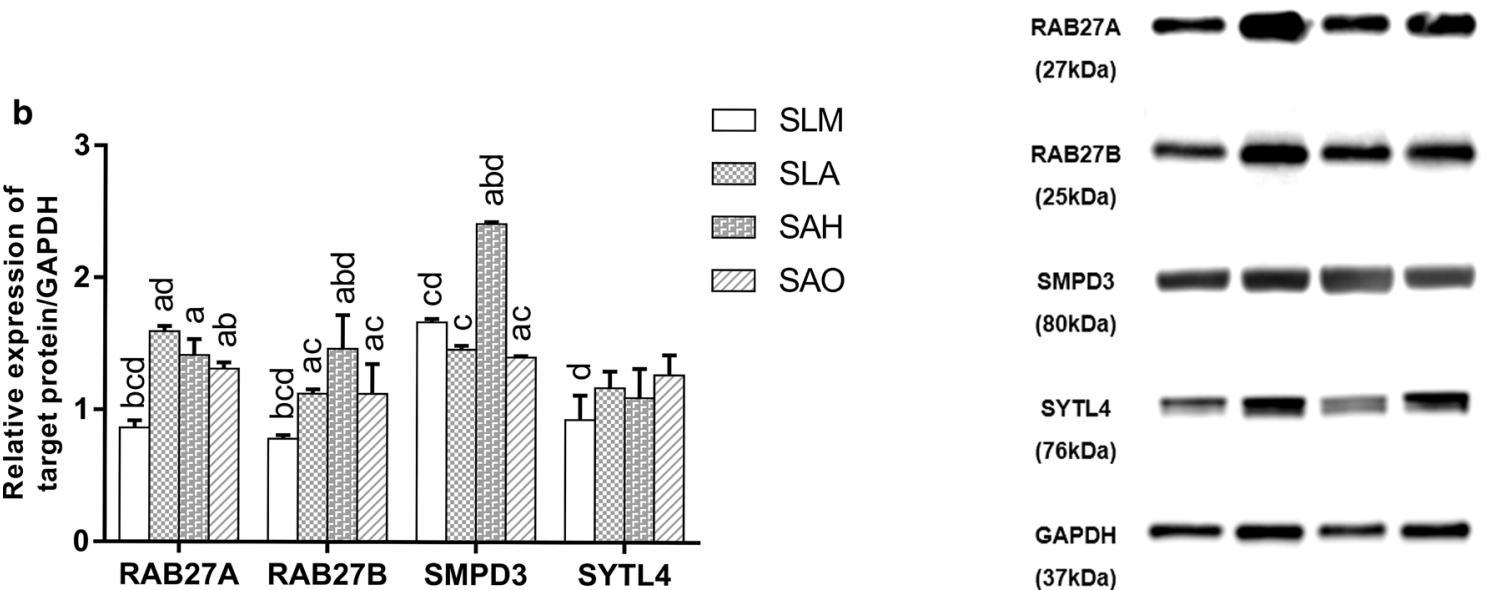

(27kDa)

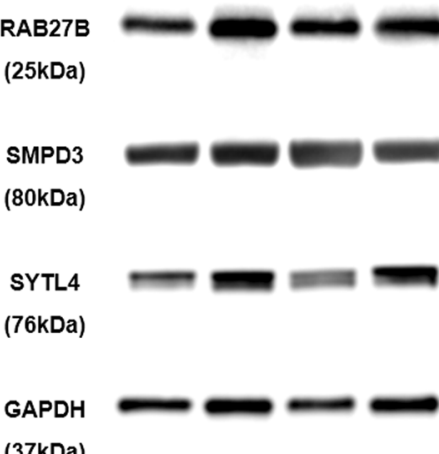

Fig. 7 Effects of titanium topography on gene and protein expression levels related to exosome secretion. Gene expression evaluation related to exosome secretion of hBMSCs on the titanium surface of each group by RT-qPCR $(\mathbf{a})(n=3)$. Protein expression evaluation related to exosome secretion of hBMSCs on the titanium surface of each group by quantitative analysis (b) of Western blotting bands $(\mathbf{c})(n=3)$. a- $d$ above each bar indicate significant difference compared to SLM, SLA, SAH, SAO respectively $(p<0.05)$

$[5,11]$. Finally, we might regulate cell-titanium activity and cell-cell communication for better osseointegration by optimizing the titanium surface topography.

\section{Conclusions}

In summary, it has been concluded that micro/nanonettextured hierarchical titanium topography promotes exosome biogenesis and extracellular secretion by upregulating RAB27B and SMPD3 gene expression and micro/ nanotube-textured hierarchical titanium topography promotes exosome secretion due to the strongest enhancement in cell proliferation for improved osseointegration. Our findings also highlight the important effects of titanium topography on regulating exosome release from BMSCs, but the detailed mechanism of the titaniumexosome-BMSCs interactions requires further study. Furthermore, the proteomic analysis of exosomal cargos from different topographies should be conducted to gain insight into the possible mechanism.

\section{Methods}

Specimen preparation and surface treatment

The titanium disks (diameter $10 \mathrm{~mm}$; thickness $1 \mathrm{~mm}$ ) and titanium implants (diameter $2.2 \mathrm{~mm}$; length $5 \mathrm{~mm}$ ) were designed by SolidWorks ${ }^{\circledR} 12.0$ software (SolidWorks Corp., USA) and manufactured by an SLM system (SLM125HL, SLM solutions GmbH, Germany) using commercially pure titanium powders (average $30 \mu \mathrm{m}$ particle size; Grade II; Western BaoDe, PR China), as previously described [30, 33]. Briefly, the laser printing parameters of the SLM disks were set to $145 \mathrm{~W}$ power, $355 \mathrm{~mm} / \mathrm{s}$ scanning velocity, $45 \mu \mathrm{m}$ layer thickness, and $50 \mu \mathrm{m}$ spot size. The SLM specimens were subsequently cleaned by compressed air and ultrasonic processing. These native titanium specimens were termed the SLM samples and used as the control group. Some of the SLM samples were sandblasted with $250 \mu \mathrm{m} \mathrm{ZrO}_{2}$ particles under constant $0.8 \mathrm{MPa}$ compressed air for $10 \mathrm{~s}$ and then immersed in 5\% hydrofluoric acid (HF) at room temperature for $2 \mathrm{~min}$. These specimens were termed the SLA samples. 


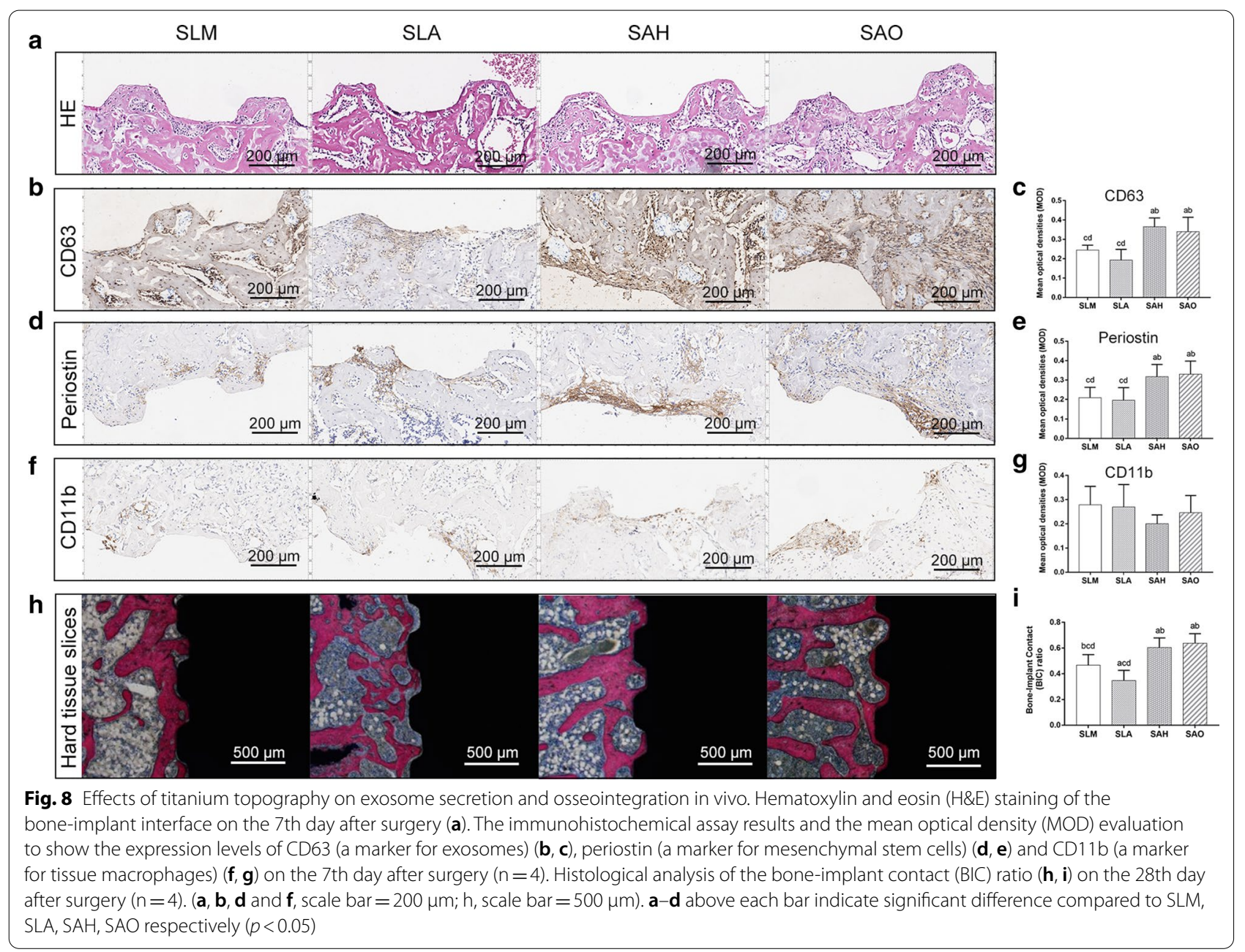

Some of the SLA samples were treated in a continuously stirring solution of $5 \mathrm{M} \mathrm{NaOH}$ in a water bath at $80{ }^{\circ} \mathrm{C}$ for $8 \mathrm{~h}$. These specimens were termed the SAH samples. Other SLA samples were incubated with $0.3 \mathrm{wt} \%$ ammonium fluoride $\left(\mathrm{NH}_{4} \mathrm{~F}\right)$ in an ethylene glycol $\left(\mathrm{C}_{2} \mathrm{H}_{6} \mathrm{O}_{2}\right)$ solution at $30 \mathrm{~V}$ for $60 \mathrm{~min}$. These specimens were termed the $\mathrm{SAO}$ samples.

Four groups, the SLM, SLA, SAH, and SAO samples were ultrasonically cleaned and sterilized before use in each experiment.

\section{Surface characterization}

The surface topography of each group was observed by field-emission scanning electron microscopy (FE-SEM; S-4800, Hitachi, Japan) and analyzed by ImageJ 1.52a software (National Institutes of Health, USA). Surface roughness parameters including arithmetic mean deviation roughness $(\mathrm{Sa})$ and root mean square roughness $(\mathrm{Sq})$ were determined using a confocal 3D surface profiler (UP-WLI, Rtec UP series, USA). Water contact angles of each group were detected using the sessiledrop method with a contact angle measuring system (OCA40 Micro, Dataphysics, Germany).

\section{Cell culture and identification assay}

Human bone marrow mesenchymal stem cells (hBMSCs; Guangzhou Jennio Biotech Co., PR China) were cultured and expanded at $37{ }^{\circ} \mathrm{C}$ and $5 \% \mathrm{CO}_{2}$ in basal growth DMEM (Gibco, USA) containing 10\% fetal bovine serum (FBS; Gibco), 1\% penicillin-streptomycin (Gibco) and 1\% GlutaMAX ${ }^{\mathrm{TM}}$ supplement (Gibco). Cells were collected at passages 3-6 upon reaching approximately $80-90 \%$ confluence for the follow-up experiments.

For the surface marker expression assay, cells at passage 3 were first blocked with $3 \%$ bovine serum albumin (BSA; Beyotime Biotech, PR China) and stained for $30 \mathrm{~min}$ with the following conjugated antibodies (BioLegend, USA): anti-CD73-PE, anti-CD29-PE, anti-CD11b-PE, anti-CD105-FITC, anti-CD45-FITC, anti-CD90-APC, 
anti-CD34-APC, anti-CD19-PE/Cy7, anti-HLA-DR-PE/ Cy7 and isotype-matched control antibodies. The cells were washed to remove unconjugated antibodies and identified for surface antigen markers by flow cytometry with a flow cytometer (CytoFLEX, Beckman, USA) and FlowJo X software (FlowJo, USA).

For the osteogenic differentiation assay, cells at passage 5 were seeded at a density of 2500 cells $/ \mathrm{mL}$ in a 6-well plate. Upon reaching $60-70 \%$ confluence, the cell culture medium was replaced with osteogenic differentiation media consisting of basal growth DMEM, $0.1 \mu \mathrm{mol} / \mathrm{L}$ dexamethasone (Sigma, USA), $50 \mu \mathrm{mol} / \mathrm{L}$ ascorbic acid (Sigma) and $10 \mathrm{mmol} / \mathrm{L} \beta$-sodium glycerophosphate (Sigma). Control cells were cultured at the same density in regular DMEM for 11 days. The osteogenic differentiation capacity of the cells was assessed by alizarin red staining and imaged at $200 \times$ magnification. For the adipogenic differentiation assay, cells at passage 5 were seeded at a density of 2500 cells $/ \mathrm{mL}$ in a 6 -well plate. When the cells reached $80-90 \%$ confluence, the cell culture medium was replaced with adipogenic differentiation media consisting of basal growth DMEM, $1 \mu \mathrm{mol} / \mathrm{L}$ dexamethasone, $10 \mathrm{mg} / \mathrm{L}$ insulin (Life, USA), $0.5 \mathrm{mmol} / \mathrm{L}$ 3-isobutyl-1-methylxanthine (Sigma) and $0.2 \mathrm{mmol} / \mathrm{L}$ indomethacin (Sigma). Control cells were cultured at the same density in regular DMEM for 11 days. The adipogenic differentiation capacity of the cells was assessed by oil red $O$ staining and imaged at $200 \times$ magnification. For the chondrogenic differentiation assay, a suspension of 300,000 cells at passage 5 was centrifuged at $1500 \mathrm{r} / \mathrm{min}$ for $5 \mathrm{~min}$ to form a pellet in a $15 \mathrm{~mL}$ sterile tube and incubated overnight. The cell culture medium was replaced with chondrogenic differentiation media consisting of basal growth DMEM, $10 \mathrm{ng} / \mathrm{mL}$ TGF $\beta-1$ (Sigma), $50 \mathrm{mg} / \mathrm{L}$ ascorbic acid, $0.1 \mathrm{nmol} / \mathrm{L}$ dexamethasone, $50 \mathrm{mg} / \mathrm{mL}$ ITS (Sigma), $1 \mathrm{mmol} / \mathrm{L}$ sodium pyruvate (Sigma), and $5.35 \mu \mathrm{g} / \mathrm{mg}$ linoleic acid (Sigma). The control cell pellet was cultured at the same density in regular DMEM for 21 days. Sections (5 $\mu$ m thickness) of the pellets were first stained with hematoxylin solution. The chondrogenic differentiation capacity of the cells was assessed by safranin O staining and imaged at $200 \times$ magnification.

\section{Cell viability evaluation}

For the cell adhesion and morphology assay, hBMSCs were incubated on the specimen surfaces at a density of 10,000 cells $/ \mathrm{mL}$ in 48 -well plates for $24 \mathrm{~h}$ and subsequently fixed in $2.5 \%$ glutaraldehyde solution overnight at $4{ }^{\circ} \mathrm{C}$. After dehydration in a gradient ethanol series (50, $75,90,95$, and $100 \%$ ) and drying in air, the specimens were sprayed with gold and detected by FE-SEM.
For the cell proliferation assay, hBMSCs were cultured on the specimen surfaces at a density of 2500 cells $/ \mathrm{mL}$ in 48-well plates for 1, 3, 5, and 7 days and evaluated using a cell counting kit-8 assay (CCK-8; Dojindo, Japan) according to the manufacturer's instructions. Briefly, $500 \mu \mathrm{L}$ of basal growth DMEM with 10\% CCK- 8 reagent was added to each well and incubated for $90 \mathrm{~min}$. The supernatant absorbance at $450 \mathrm{~nm}$ of each group was measured at predetermined time points.

\section{Isolation and characterization of the exosomes}

Cells in culture medium with $10 \%$ exosome-depleted FBS (BI, Israel) were seeded on the specimen surfaces at a density of 40,000 cells $/ \mathrm{mL}$ in 48 -well plates for $48 \mathrm{~h}$. The hBMSCs-released exosomes were extracted by an exosome isolation kit (EIQ3, H-Wayen, PR China) according to the manufacturer's instructions. Briefly, supernatants were first centrifuged at $3000 \times g$ for $15 \mathrm{~min}$ to remove the cells and cell debris and then mixed with the isolation regent (at half the volume of the supernatant) at $4{ }^{\circ} \mathrm{C}$ overnight. After incubation, the exosomes in the mixture were precipitated by centrifugation at $3000 \times g$ for $60 \mathrm{~min}$ and resuspended in $1 \mathrm{~mL}$ of the supernatant from above. The resuspensions were centrifuged at $10,000 \times g$ for $10 \mathrm{~min}$. Then, the pellets were resuspended in $200 \mu \mathrm{L}$ of PBS and further purified by centrifugation at $10,000 \times g$ for $5 \mathrm{~min}$. The supernatant contained the exosomes, and all steps were performed at $4{ }^{\circ} \mathrm{C}$.

Transmission electron microscopy (TEM), nano-flow cytometry, flow cytometry and western blotting were used to identify the exosomes. Briefly, $10 \mu \mathrm{L}$ of exosome preparations were placed onto a copper mesh and deposited for $3 \mathrm{~min}$. The samples were first negatively stained with phosphotungstic acid, dried for $5 \mathrm{~min}$, and then imaged by TEM (JEM-1200EX, Japan Electronics Co., Ltd, Japan) operating at $80-120 \mathrm{kV}$. For particle size analysis, the exosome preparations, standard silica particles, and blank controls (PBS) were detected with nano-flow cytometry (Flow NanoAnalyzer, NanoFCM, PR China) at a low feed pressure $(\leq 1.0 \mathrm{kPa})$ under the same conditions (laser power and scattering channel attenuation coefficient). Standard working curves for the silica particles between the scattered light intensity and the particle size were established to calculate the particle size distribution of the samples. For phenotyping analysis, $100 \mu \mathrm{L}$ of exosome preparations were stained for $30 \mathrm{~min}$ with FITC-conjugated antibodies (BD, USA), including mouse-anti-human CD63 and mouse-anti-human CD81, and ultracentrifuged (Optima L-100xp, Beckman, USA) at $100,000 \mathrm{~g}$ for $20 \mathrm{~min}$. The pellets were resuspended in PBS for flow cytometry (Accuri C6, BD, USA). Western blotting was conducted to examine exosome positive markers (CD9, 
CD63 and TSG101) and an exosome negative marker (Calnexin). The proteins from the exosome sample and culture medium with $10 \%$ exosome-depleted FBS (blank control) were extracted by RIPA lysis buffer and quantified by a BCA Protein Assay Kit (exosome sample: $0.72 \mu \mathrm{g} / \mu \mathrm{L}$, control: $0.46 \mu \mathrm{g} / \mu \mathrm{L}$ ). Equal amounts of proteins $(20 \mu \mathrm{g})$ from each sample were tested according to the standard protocols of western blotting, which is described in the western blotting section of methods. The primary antibody information is as follows: rabbit anti-CD9 (1:1,000; SBI, USA), rabbit anti-CD63 (1:1,000; SBI), rabbit anti-TSG101 (1:1,000; SBI) and rabbit anti-Calnexin (1:1,000; Immunoway, USA). The secondary antibody information is as follows: exosome validated goat anti-rabbit IgG (CD9, CD63 and TSG101; 1:5000; SBI) and BeriBlot for IP Detection Reagent (Calnexin, 1:2000; Abcam, UK).

\section{Assessment of acetylcholinesterase (AChE) activity}

An Amplex ${ }^{\circledR}$ Red Acetylcholine/Acetylcholinesterase Assay Kit (Thermo Fisher, USA) was used to determine the acetylcholinesterase (AChE) activity of the exosomes released into the supernatant. Briefly, $10 \mu \mathrm{L}$ of exosome preparations from each group was first diluted to $100 \mu \mathrm{L}$ in $1 \times$ reaction buffer and then added to a 96-well black flat-bottomed microplate (Greiner, Germany). Next, $100 \mu \mathrm{L}$ of working solution containing Amplex Red reagent/HRP/choline oxidase/acetylcholine was pipetted into each microplate well containing the exosome samples and blank controls. The final reaction volume of $200 \mu \mathrm{L}$ was incubated for $30 \mathrm{~min}$ at room temperature away from light. The fluorescence was measured in a fluorescence microplate reader $\left(\right.$ GloMax ${ }^{\circledR}$-Multi Detection System, Promega, USA) using emission detection at $590 \mathrm{~nm}$ and was then corrected for background fluorescence by subtracting the value from the PBS control.

\section{Immunofluorescent staining}

For intracellular distribution of CD63 in the hBMSCs after incubation for $48 \mathrm{~h}$ on different titanium topographies, cells were fixed with $4 \%$ paraformaldehyde for 10 min and blocked with PBS containing $0.1 \%$ Triton $\mathrm{X}-100$ and $1 \%$ bovine serum albumin for $30 \mathrm{~min}$. The cells on the titanium samples were first incubated with rabbit anti-CD63 (1:200; Immunoway) at $4{ }^{\circ} \mathrm{C}$ overnight and stained with goat anti-rabbit Alexa Fluor 488 IgG H\&L antibody (1:500; Abcam) and DAPI-containing mounting medium (Beyotime). Images of the immunofluorescent staining were captured with a confocal laser scanning microscope (LSM780, Carl Zeiss Meditec AG, Germany).

\section{Quantitative real-time polymerase chain reaction (qRT-PCR)}

Total RNA from the hBMSCs after incubation on the titanium sample for $48 \mathrm{~h}$ was extracted by a Direct-zol ${ }^{\mathrm{TM}}$ RNA MiniPrep Kit (Zymo Research, USA) following the manufacturer's instructions. cDNA from each group was synthesized using a PrimeScript ${ }^{\mathrm{TM}} \mathrm{RT}$ Master Mix Kit (Takara, Japan), followed by qRT-PCR on a Roche LightCycler $^{\circledR} 96$ System using LightCycler ${ }^{\circledR} 480$ SYBR Green I Master (Roche, Switzerland). The primers for the target genes related to biogenesis and secretion of exosomes were as follows: RAB27A F: $5^{\prime}$-GATGCTTCT GGACCTGATAATGA-3', R: 5'-CCACCTGAACTACTA TGTCGCTT-3'; RAB27B F: 5'-GCCCTCACAGAGACA CTAACACAG-3', R: 5'-GTGAGGAGACCAAGAGAA GGCA-3'; SMPD3 F: 5'-ATGGACGTGGCCTATCAC TGTT-3', R: 5'-CTTGAGAAACAGAGCTCCCTTAGA -3'; and GAPDH F: 5'-GAACGGGAAGCTCACTGG-3', R: 5'-GCCTGCTTCACCACCTTCT-3'.

\section{Western blot (WB)}

The proteins from the hBMSCs after incubation on the titanium sample for $48 \mathrm{~h}$ were extracted by RIPA lysis buffer containing protease and phosphatase inhibitors (Beyotime) and quantified by a BCA Protein Assay Kit (Cowin Bio., PR China). Then, $20 \mu \mathrm{g}$ of protein from each sample was loaded on a $12 \%$ precast mini polyacrylamide gel (GenScript, USA) and transferred to a PVDF membrane (Millipore, USA). The membrane was blocked with $5 \%$ skim milk (BD) dissolved in $1 \times$ Tris-buffered saline with Tween (TBST; Cowin Bio.) and probed with the following primary antibodies at $4{ }^{\circ} \mathrm{C}$ overnight: rabbit monoclonal anti-RAB27A (1:1000; Abcam), rabbit monoclonal anti-GAPDH (1:1000; CST, USA), rabbit polyclonal anti-RAB27B (1:1000; Abclonal, PR China), rabbit polyclonal anti-SMPD3 (1:1000; Abclonal) and rabbit polyclonal anti-SYTL4 (1:1000; Immunoway). The membrane was then incubated at room temperature for $1 \mathrm{~h}$ with goat anti-rabbit IgG (1:20,000; CST). The probed blots were developed using an ECL reagent (Millipore) and detected with a chemiluminescence imaging system (GeneGnome XRQ, USA).

\section{Animal experiment}

The study protocol was approved by the Institutional Animal Care and Use Committee (IACUC) of Sun Yat-Sen University (Approval No. SYSU-IACUC-2020-000352). Thirty-two male SD rats (Laboratory Animal Center, Sun Yat-sen University, Guangzhou, China) weighing 200-250 g were used for this experiment. Anesthesia was induced by injecting pentobarbital sodium $(2.5 \mathrm{mg} /$ $\mathrm{kg}$, intraperitoneally). In the left and right distal femoral 
bone planes, implant drilling holes with a diameter of $2.2 \mathrm{~mm}$ were prepared and randomly assigned to one of the above 4 titanium implant groups. The implants were directly placed and submerged for healing. Seven and 28 days after surgery, rats were sacrificed by injection of an overdose of pentobarbital sodium, and the distal femoral bone blocks containing the implants were collected and fixed in $10 \%$ formaldehyde for histological analysis.

\section{Immunohistochemistry and histological evaluation}

The specimens euthanized after 7 days were decalcified in $10 \%$ ethylenediaminetetraacetic acid (EDTA) for 45 days and embedded in paraffin. The implants were unscrewed and 5- $\mu \mathrm{m}$-thick sections were prepared and stained with hematoxylin and eosin (H\&E). For immunohistochemistry, sections were incubated with rabbit anti-CD63 antibody (1:100; Abclonal), rabbit anti-periostin antibody (1:1000; Abcam) and rabbit anti-CD11b antibody (1:4000; Abcam) overnight at $4{ }^{\circ} \mathrm{C}$ followed by incubation with a horseradish peroxidase (HRP)-conjugated secondary antibody. Sections were examined with a digital pathology scanner (Aperio AT2; Leica Biosystems, USA) and evaluated by calculating the mean optical density (MOD) of CD63, periostin and CD11b expression using Image-Pro Plus 6.0 (Media Cybernetics, USA).

The specimens euthanized after 28 days were dehydrated in a gradient series of ethanol and embedded in polymethylmethacrylate. Sections with a final thickness of $50 \mu \mathrm{m}$ were prepared using a saw (Leica SP1600; Leica Biosystems) and stained with methylene blue acid solution. Digital images at $25 \times$ magnification were acquired with an Axio Imager.Z2 (Zeiss) and analyzed for the bone-implant contact (BIC) ratio with Image-Pro Plus.

\section{Statistics}

Each experiment was repeated three times. For the description of the data, all values are expressed as the mean \pm standard deviation and were analyzed using the SPSS 25.0 software package (SPSS Inc., USA). One-way ANOVA was used to determine the level of significance. Differences among the groups were analyzed with the Student-Newman-Keuls correction. The level of significance was set at $p<0.05$.

\begin{abstract}
Abbreviations
AChE: Acetylcholinesterase; BMSCs: Bone marrow mesenchymal stem cells; EVs: Extracellular vesicles; qRT-PCR: Quantitative real-time polymerase chain reaction; SAH: Alkali-heat treatment; SAO: Anodic oxidation; SLM: Selective laser melting; SMPD3: Sphingomyelin phosphodiesterase 3; WB: Western blot.
\end{abstract}

\section{Acknowledgements}

The authors wish to thank all of the research staff members at the Department of Oral Implantology, Guanghua School of Stomatology, Sun Yat-sen
University. The work was supported by the Guangdong Provincial Science and Technology Major Project (No. 2017B090912004).

\section{Authors' contributions}

ZZ conceived and designed the overall study, executed the experiments, analyzed the data, and wrote the manuscript. RX executed the experiments, analyzed data. YaY and $\mathrm{CL}$ analyzed the data, XY, YL, TW and YiY edited the manuscript. FD supervised the project and made final approval of manuscript. All authors read and approved the final manuscript.

\section{Funding}

This study was supported by a grant from Guangdong Provincial Science and Technology Major Project (No. 2017B090912004).

\section{Availability of data and materials}

All data generated or analyzed during this study are included in this published article.

\section{Declarations}

Ethics approval and consent to participate

The study protocol for the animal experiment was approved by the Institutional Animal Care and Use Committee (IACUC) of Sun Yat-Sen University (Approval No. SYSU-IACUC-2020-000352).

\section{Consent for publication}

Not applicable.

\section{Competing interests}

The authors declare that they have no competing interests.

\section{Author details}

1 Department of Oral Implantology, Hospital of Stomatology, Guanghua School of Stomatology, Sun Yat-Sen University, No.56 of LingYuanXiLu, Guangzhou 510055, Guangdong, People's Republic of China. ${ }^{2}$ Guangdong Provincial Key Laboratory of Stomatology, Guangzhou, People's Republic of China.

Received: 23 December 2020 Accepted: 9 March 2021

Published online: 19 March 2021

\section{References}

1. Giro G, Chambrone L, Goldstein A, Rodrigues JA, Zenobio E, Feres M, Figueiredo LC, Cassoni A, Shibli JA. Impact of osteoporosis in dental implants: a systematic review. World J Orthop. 2015;6:311-5.

2. Esposito M, Hirsch JM, Lekholm U, Thomsen P. Biological factors contributing to failures of osseointegrated oral implants. (II). Etiopathogenesis. Eur J Oral Sci. 1998;106:721-64.

3. Huang $T$, Yu Z, Yu Q, Wang Y, Jiang Z, Wang $H$, Yang G. Inhibition of osteogenic and adipogenic potential in bone marrow-derived mesenchymal stem cells under osteoporosis. Biochem Biophys Res Commun. 2020;525:902-8.

4. Terheyden H, Lang NP, Bierbaum S, Stadlinger B. Osseointegration—communication of cells. Clin Oral Implants Res. 2012;23:1127-35.

5. Wang X, Shah FA, Vazirisani F, Johansson A, Palmquist A, Omar O, Ekström $\mathrm{K}$, Thomsen P. Exosomes influence the behavior of human mesenchymal stem cells on titanium surfaces. Biomaterials. 2020;230:119571.

6. Cha C, Liechty WB, Khademhosseini A, Peppas NA. Designing biomaterials to direct stem cell fate. ACS Nano. 2012;6:9353-8.

7. Yin L, Chang Y, You Y, Liu C, Li J, Lai HC. Biological responses of human bone mesenchymal stem cells to Ti and TiZr implant materials. Clin Implant Dent Relat Res. 2019;21:550-64.

8. Golchin A, Hosseinzadeh S, Ardeshirylajimi A. The exosomes released from different cell types and their effects in wound healing. J Cell Biochem. 2018;119:5043-52.

9. Kalluri R, LeBleu VS. The biology, function, and biomedical applications of exosomes. Science. 2020;367(6478):eaau6977.

10. van Niel G, D'Angelo G, Raposo G. Shedding light on the cell biology of extracellular vesicles. Nat Rev Mol Cell Biol. 2018;19:213-28. 
11. Zhang J, Liu X, Li H, Chen C, Hu B, Niu X, Li Q, Zhao B, Xie Z, Wang Y. Exosomes/tricalcium phosphate combination scaffolds can enhance bone regeneration by activating the PI3K/Akt signaling pathway. Stem Cell Res Ther. 2016;7:136.

12. Liu X, Yang Y, Li Y, Niu X, Zhao B, Wang Y, Bao C, Xie Z, Lin Q, Zhu L. Integration of stem cell-derived exosomes with in situ hydrogel glue as a promising tissue patch for articular cartilage regeneration. Nanoscale. 2017:9:4430-8.

13. Cui Y, Luan J, Li H, Zhou X, Han J. Exosomes derived from mineralizing osteoblasts promote ST2 cell osteogenic differentiation by alteration of microRNA expression. FEBS Lett. 2016;590:185-92.

14. Menck K, Sönmezer C, Worst TS, Schulz M, Dihazi GH, Streit F, Erdmann G, Kling S, Boutros M, Binder C, Gross JC. Neutral sphingomyelinases control extracellular vesicles budding from the plasma membrane. J Extracell Vesicles. 2017;6:1378056.

15. Ruan XF, Ju CW, Shen Y, Liu YT, Kim IM, Yu H, Weintraub N, Wang XL, Tang Y. Suxiao Jiuxin pill promotes exosome secretion from mouse cardiac mesenchymal stem cells in vitro. Acta Pharmacol Sin. 2018;39:569-78.

16. Ostrowski M, Carmo NB, Krumeich S, Fanget I, Raposo G, Savina A, Moita CF, Schauer K, Hume AN, Freitas RP, Goud B, Benaroch P, Hacohen N, Fukuda M, Desnos C, Seabra MC, Darchen F, Amigorena S, Moita LF, Thery C. Rab27a and Rab27b control different steps of the exosome secretion pathway. Nat Cell Biol. 2010;12:19-30; Suppl pp. 11-13.

17. Guo BB, Bellingham SA, Hill AF. The neutral sphingomyelinase pathway regulates packaging of the prion protein into exosomes. J Biol Chem. 2015;290:3455-67.

18. Wei F, Li M, Crawford R, Zhou Y, Xiao Y. Exosome-integrated titanium oxide nanotubes for targeted bone regeneration. Acta Biomater. 2019;86:480-92.

19. Hayes JS, Khan IM, Archer CW, Richards RG. The role of surface microtopography in the modulation of osteoblast differentiation. Eur Cell Mater. 2010;20:98-108.

20. Annunziata M, Oliva A, Buosciolo A, Giordano M, Guida A, Guida L. Bone marrow mesenchymal stem cell response to nano-structured oxidized and turned titanium surfaces. Clin Oral Implants Res. 2012;23:733-40.

21. Zhu W, Teel G, O'Brien CM, Zhuang T, Keidar M, Zhang LG. Enhanced human bone marrow mesenchymal stem cell functions on cathodic arc plasma-treated titanium. Int J Nanomed. 2015;10:7385-96.

22. Rana M, Gellrich MM, Gellrich NC. Customised reconstruction of the orbital wall and engineering of selective laser melting (SLM) core implants. Br J Oral Maxillofac Surg. 2015;53:208-9.

23. Wysocki B, Idaszek J, Zdunek J, Rozniatowski K, Pisarek M, Yamamoto A, Swieszkowski W. The influence of selective laser melting (SLM) process parameters on in-vitro cell response. Int J Mol Sci. 2018;19:1619.

24. Shaoki A, Xu JY, Sun H, Chen XS, Ouyang J, Zhuang XM, Deng FL. Osseointegration of three-dimensional designed titanium implants manufactured by selective laser melting. Biofabrication. 2016;8:045014.

25. Gittens RA, McLachlan T, Olivares-Navarrete R, Cai Y, Berner S, Tannenbaum R, Schwartz Z, Sandhage KH, Boyan BD. The effects of combined micron-/submicron-scale surface roughness and nanoscale features on cell proliferation and differentiation. Biomaterials. 2011;32:3395-403.

26. Wang X, Xu S, Zhou S, Xu W, Leary M, Choong P, Qian M, Brandt M, Xie YM. Topological design and additive manufacturing of porous metals for bone scaffolds and orthopaedic implants: a review. Biomaterials. 2016;83:127-41

27. Abdelhamid HN, Dowaidar M, Hällbrink M, Langel Ü. Gene delivery using cell penetrating peptides-zeolitic imidazolate frameworks. Microporous Mesoporous Mater. 2020;300:110173.

28. Abdelhamid HN, Dowaidar M, Langel Ü. Carbonized chitosan encapsulated hierarchical porous zeolitic imidazolate frameworks nanoparticles for gene delivery. Microporous Mesoporous Mater. 2020;302:110200.

29. Wu L, Zhou C, Zhang B, Lei H, Wang W, Pu X, Liu L, Liang J, Fan Y, Zhang $X$. Construction of biomimetic natural wood hierarchical porousstructure bioceramic with micro/nanowhisker coating to modulate cellular behavior and osteoinductive activity. ACS Appl Mater Interfaces. 2020;12:48395-407.

30. Xu JY, Chen XS, Zhang CY, Liu Y, Wang J, Deng FL. Improved bioactivity of selective laser melting titanium: Surface modification with micro-/nanotextured hierarchical topography and bone regeneration performance evaluation. Mater Sci Eng C Mater Biol Appl. 2016;68:229-40.
31. Wang W, Zhao L, Wu K, Ma Q, Mei S, Chu PK, Wang Q, Zhang Y. The role of integrin-linked kinase/beta-catenin pathway in the enhanced MG63 differentiation by micro/nano-textured topography. Biomaterials. 2013;34:631-40.

32. Ferraris S, Bobbio A, Miola M, Spriano S. Micro- and nano-textured, hydrophilic and bioactive titanium dental implants. Surf Coat Tech. 2015;276:374-83.

33. $X u$ RG, Hu XC, Yu XL, Wan SQ, Wu F, Ouyang JL, Deng FL. Micro-/nanotopography of selective laser melting titanium enhances adhesion and proliferation and regulates adhesion-related gene expressions of human gingival fibroblasts and human gingival epithelial cells. Int J Nanomed. 2018;13:5045-57.

34. Zhuang XM, Zhou B, Yuan KF. Role of p53 mediated miR-23a/CXCL12 pathway in osteogenic differentiation of bone mesenchymal stem cells on nanostructured titanium surfaces. Biomed Pharmacother. 2019;112:108649.

35. Li G, Song Y, Shi M, Du Y, Wang W, Zhang Y. Mechanisms of Cdc42-mediated rat MSC differentiation on micro/nano-textured topography. Acta Biomater. 2017;49:235-46.

36. Mohammed MT, Semelov VG, Sotov AV. SLM-built titanium materials: great potential of developing microstructure and properties for biomedical applications: a review. Mater Res Express. 2019;6:122006.

37. Sing SL, An J, Yeong WY, Wiria FE. Laser and electron-beam powder-bed additive manufacturing of metallic implants: a review on processes, materials and designs. J Orthop Res. 2016;34:369-85.

38. Hasegawa M, Saruta J, Hirota M, Taniyama T, Sugita Y, Kubo K, Ishijima M, Ikeda T, Maeda H, Ogawa T. A newly created meso-, micro-, and nanoscale rough titanium surface promotes bone-implant integration. Int J Mol Sci. 2020;21:783.

39. Nazarov DV, Zemtsova EG, Solokhin AY, Valiev RZ, Smirnov VM. Modification of the surface topography and composition of ultrafine and coarse grained titanium by chemical etching. Nanomaterials (Basel). 2017;7:15.

40. Hung KY, Lin YC, Feng HP. The effects of acid etching on the nanomorphological surface characteristics and activation energy of titanium medical materials. Materials (Basel). 2017;10:1164.

41. Fu Q, Bellare A, Cui Y, Cheng B, Xu S, Kong L. The effect of hierarchical micro/nanotextured titanium implants on osseointegration immediately after tooth extraction in beagle dogs. Clin Implant Dent Relat Res. 2017;19:486-95.

42. Rasouli $\mathrm{R}$, Barhoum A, Uludag $\mathrm{H}$. A review of nanostructured surfaces and materials for dental implants: surface coating, patterning and functionalization for improved performance. Biomater Sci. 2018;6:1312-38.

43. Yamada M, Kato E, Yamamoto A, Sakurai K. A titanium surface with nanoordered spikes and pores enhances human dermal fibroblastic extracellular matrix production and integration of collagen fibers. Biomed Mater. 2016:11:015010.

44. Fu J, Liu X, Tan L, Cui Z, Liang Y, Li Z, Zhu S, Zheng Y, Kwok Yeung KW, Chu PK, Wu S. Modulation of the mechanosensing of mesenchymal stem cells by laser-induced patterning for the acceleration of tissue reconstruction through the $W n t / \beta$-catenin signaling pathway activation. Acta Biomater. 2020;101:152-67.

45. Su EP, Justin DF, Pratt CR, Sarin VK, Nguyen VS, Oh S, Jin S. Effects of titanium nanotubes on the osseointegration, cell differentiation, mineralisation and antibacterial properties of orthopaedic implant surfaces. Bone Joint J. 2018;100-B(1 Supple A):9-16.

46. Wang N, Li H, Lu W, Li J, Wang J, Zhang Z, Liu Y. Effects of TiO2 nanotubes with different diameters on gene expression and osseointegration of implants in minipigs. Biomaterials. 2011;32:6900-11.

47. von Wilmowsky C, Bauer S, Roedl S, Neukam FW, Schmuki P, Schlegel KA. The diameter of anodic $\mathrm{TiO} 2$ nanotubes affects bone formation and correlates with the bone morphogenetic protein-2 expression in vivo. Clin Oral Implants Res. 2012;23:359-66.

48. Albrektsson T, Wennerberg A. Oral implant surfaces: Part 1-review focusing on topographic and chemical properties of different surfaces and in vivo responses to them. Int J Prosthodont. 2004;17:536.

49. Nicolas-Silvente Al, Velasco-Ortega E, Ortiz-Garcia I, Monsalve-Guil L, Gil J, Jimenez-Guerra A. Influence of the titanium implant surface treatment on the surface roughness and chemical composition. Materials (Basel). 2020;13:314

50. Vasak C, Busenlechner D, Schwarze UY, Leitner HF, Munoz GF, Hefti T, Schlottig F, Gruber R. Early bone apposition to hydrophilic and 
hydrophobic titanium implant surfaces: a histologic and histomorphometric study in minipigs. Clin Oral Implants Res. 2014;25:1378-85.

51. Donos N, Horvath A, Calciolari E, Mardas N. Immediate provisionalization of bone level implants with a hydrophilic surface. A five-year follow-up of a randomized controlled clinical trial. Clin Oral Implants Res. 2019;30:139-49.

52. Kunzler TP, DrobekT, Schuler M, Spencer ND. Systematic study of osteoblast and fibroblast response to roughness by means of surfacemorphology gradients. Biomaterials. 2007;28:2175-82.

53. Dalby MJ. Cellular response to low adhesion nanotopographies. Int J Nanomed. 2007:2:373-81.

54. Tian Y, Ma L, Gong M, Su G, Zhu S, Zhang W, Wang S, Li Z, Chen C, Li L, Wu $L$, Yan X. Protein profiling and sizing of extracellular vesicles from colorectal cancer patients via flow cytometry. ACS Nano. 2018;12:671-80.

55. Baglio SR, Rooijers K, Koppers-Lalic D, Verweij FJ, Perez LM, Zini N, Naaijkens B, Perut F, Niessen HW, Baldini N, Pegtel DM. Human bone marrow- and adipose-mesenchymal stem cells secrete exosomes enriched in distinctive miRNA and tRNA species. Stem Cell Res Ther. 2015;6:127.
56. Zheng Y, Campbell EC, Lucocq J, Riches A, Powis SJ. Monitoring the Rab27 associated exosome pathway using nanoparticle tracking analysis. Exp Cell Res. 2013;319:1706-13.

57. Biguetti CC, Cavalla F, Silveira EM, Fonseca AC, Vieira AE, Tabanez AP, Rodrigues DC, Trombone APF, Garlet GP. Oral implant osseointegration model in C57BI/6 mice: microtomographic, histological, histomorphometric and molecular characterization. J Appl Oral Sci. 2018. https://doi.org/10.1590/ 1678-7757-2017-0601.

\section{Publisher's Note}

Springer Nature remains neutral with regard to jurisdictional claims in published maps and institutional affiliations.
Ready to submit your research? Choose BMC and benefit from:

- fast, convenient online submission

- thorough peer review by experienced researchers in your field

- rapid publication on acceptance

- support for research data, including large and complex data types

- gold Open Access which fosters wider collaboration and increased citations

- maximum visibility for your research: over $100 \mathrm{M}$ website views per year

At BMC, research is always in progress.

Learn more biomedcentral.com/submissions 